\title{
An Interaction Theory-based New Distance Teaching Model for Cross Talk
}

\author{
https://doi.org/10.3991/ijet.v13i06.8588 \\ Zhuang Zhou \\ University of Science and Technology Liaoning, Anshan, Liaoning \\ zhouzhuangaskd@163.com
}

\begin{abstract}
At present, most distance education platforms are often featured by the lack of specialty, only deposit teaching resources on the server, and fail to meet students' needs of selective learning and periodical learning. Secondly, there is no Internet-based online teaching platform system in the current technology to support interactive teaching services. In order to improve the teaching effect, a teaching model was proposed in this study to apply the new distance education technology integrated with interaction theory into art performance courses. The concrete combination method was introduced using the course of Cross Talk as an example. From the comparison between the traditional teaching model and the improved teaching model, it can be seen that integration of the new distance learning model into the teaching of Cross Talk can enhance the teaching effect and improve students' learning attitude. Moreover, the courseware resources and interactive Q\&A module provided via the platform can assist students to reinforce their comprehension of all the knowledge, more intuitively recognize the characteristics of Cross Talk as an art performance course and meet the requirements of modern society on art performance graduates.
\end{abstract}

Keywords-Cross Talk, teaching model, reform, teaching effect

\section{Introduction}

The birth of the Internet has promoted the development of information technology, which has further brought many changes to people's lives. Following the derivative products induced by information technology, travel, tourism, shopping, finance and other aspects have demonstrated new features [1]. At the same time, higher education models and teaching approaches have also gone through corresponding technical and structural innovations with the development of information technology. Based on the Internet and local area networks in the information age, the construction of digital campuses with new features has become an inevitable trend for higher education and is regarded as an effective foundation for the implementation of a new education model in colleges and universities [2], namely, the new distance teaching model proposed in this study. This model works through the Internet and realizes multiple purposes such as information management, classroom teaching and resource sharing. 
Currently, many colleges and universities in China have effectively applied the new distance teaching model put forward in this study to course teaching, including a number of excellent national courses such as Advanced Mathematics [3], College English [4], An introduction to Socialism with Chinese characteristics [5] and other courses, proving that the new distance teaching model can effectively meet the corresponding teaching requirements of higher education.

Meanwhile, in the construction and development of the new distance model, the model can effectively enhance the enthusiasm of students, break the traditional oneway teacher teaching model and meet the requirements of network-based open teaching. The new distance model not only allows students to browse appropriate teaching resources provided by teachers, but also enables teachers and students to engage in interactive counseling. The new distance model proposed in this study can availably improve the teaching efficiency and teaching level in higher education course, so as to provide more skillful talents for the society.

\section{State of the art}

At present, Israel is the nation that started to use distance education technology earlier than others and has a wider application range. Particularly, the Israeli government implements an agricultural science and technology distance education platform throughout the country. The platform is applied not only to higher education but also to the dissemination of agricultural science and technology nationwide. Besides, the Israeli government has also established a nationwide agricultural science and technology distance education platform based on agricultural science and technology distance education [6]. Malinovski et al. [7] predicted the enthusiasm of students using the distance learning platform by constructing a structural equation model, found that the learning enthusiasm of students is directly influenced by the interaction between teachers and students, and suggested the use of this platform as one of the methods of distance teaching reform. In the field of art performance teaching, many researchers at home and abroad have put forward their own suggestions on how to improve students' learning attitude in art performance courses. For example, research proposed that distance education in the major of art should pay attention to diversified content, and highlighted the necessity to improve the teaching effect by providing students with diversified teaching experience based on the construction of theories [8]. Salman et al. [9] created Khan Academy, a type of educational institution which has a correspondingly significant impact on the field of online education worldwide. The "flipped classroom" education model thereby developed is used in the teaching of art performance, further changing people's view of the traditional teaching model. The entire video education process lasts about ten minutes. This model of education has also been recognized by students. The research on distance education platform in China started gradually from the end of the 20th century. To date, through cooperating with local education and broadcasting departments, Tsinghua University has established more than 120 distance education stations for its courses, forming a distance education network that combines the Internet with television and broadcasting net- 
works [10]. Through distance education video classrooms, art performance students can watch online teaching by corresponding lecturers in real time via television, computer and other multimedia devices. Online teaching also enables the user to get some excellent performance videos of the teacher [11]. In addition, with access to classroom videos and courseware that have been recorded for distance education technology broadcasting, students can organize collective learning or independent learning. School of art in Xi'an Jiaotong University in China adopts a CERNET multimedia distance education platform based on the Internet and satellite network. This distance education platform can organically combine satellite communication and campus LAN, forming an open and standardized multimedia distance education system [12].

Taking a broad view, it can be seen that the development of distance education platforms at home and abroad has begun to take shape. Corresponding "virtual universities" and digitized campus websites have emerged in some higher education institutions and research institutes, accompanied by the constant expansion and promotion of using distance education platforms. However, there are still some shortcomings in this aspect. For example, most distance education platforms in China are used by those who have already graduated. These distance learners can only normal spare time, which is fragmented, so that it is difficult for them to follow the distance teaching classes on time; second, most distance education platforms are often featured by the lack of specialty, only deposit teaching resources on the server, and fail to meet students' needs of selective learning and periodical learning. Secondly, there is no Internet-based online teaching platform system in the current technology to support interactive teaching services.

To solve the existing problems in the teaching process mentioned in the introduction part, it was proposed in this study based on the literature review above that the new distance education information technology can be incorporated into the teaching process. On the one hand, the combination of modern technology and traditional theoretical knowledge can enrich the teaching content and improve students' learning attitude. On the other hand, teachers can also interact with students in time, share teaching experience with them, cultivate their interest in learning, enhance their cognitive ability to absorb knowledge, and lead them to truly apply their knowledge. More details are given in the following sections.

\section{Specific Ways of Integrating the New Distance Education Technology into the Teaching of Cross Talk}

The interaction theory-based new distance teaching model proposed in this study uses two main theories in order to meet the teaching requirements of art courses such as Cross Talk. The first theory is interaction theory applied in the whole course teaching process. By connecting the lecturer and the imparted knowledge with the students on the other side of the screen during the whole online course, this teaching method not only enriches the learning process in the whole class, but also enhances students' interest in learning. The second theory is a new micro-video distance education model based on database. This distance education model system overcomes some shortcom- 
ings of the original distance education course resource system including instability and slow transmission. All the course learning resources are integrated into the database, thereby effectively meeting the individual needs of students in learning.

\subsection{Integrating interaction theory into distance education}

Interaction theory is the main theory that runs through the new distance education model proposed in this study. In terms of distance classroom education, we need to deepen the study of interaction theory and improve the interaction between users of distance education and classroom teaching content as well as teachers. In other words, interactive teaching should be implemented in distance education. In fact, interactive teaching emphasizes mutual support and promotion among learners. Teachers should help students discuss on their understanding of the text, deepen students' comprehension of the whole teaching content through vivid examples, lead students to identify their own learning purposes, and also make timely feedback on students' learning. Corresponding classroom teaching conducted via interactive theory cannot only improve students' interest in learning, but also enhance their learning efficiency in distance education courses and reinforce their subjective initiative in distance education. The framework of applying interaction theory to the distance education platform is shown in Figure 1.

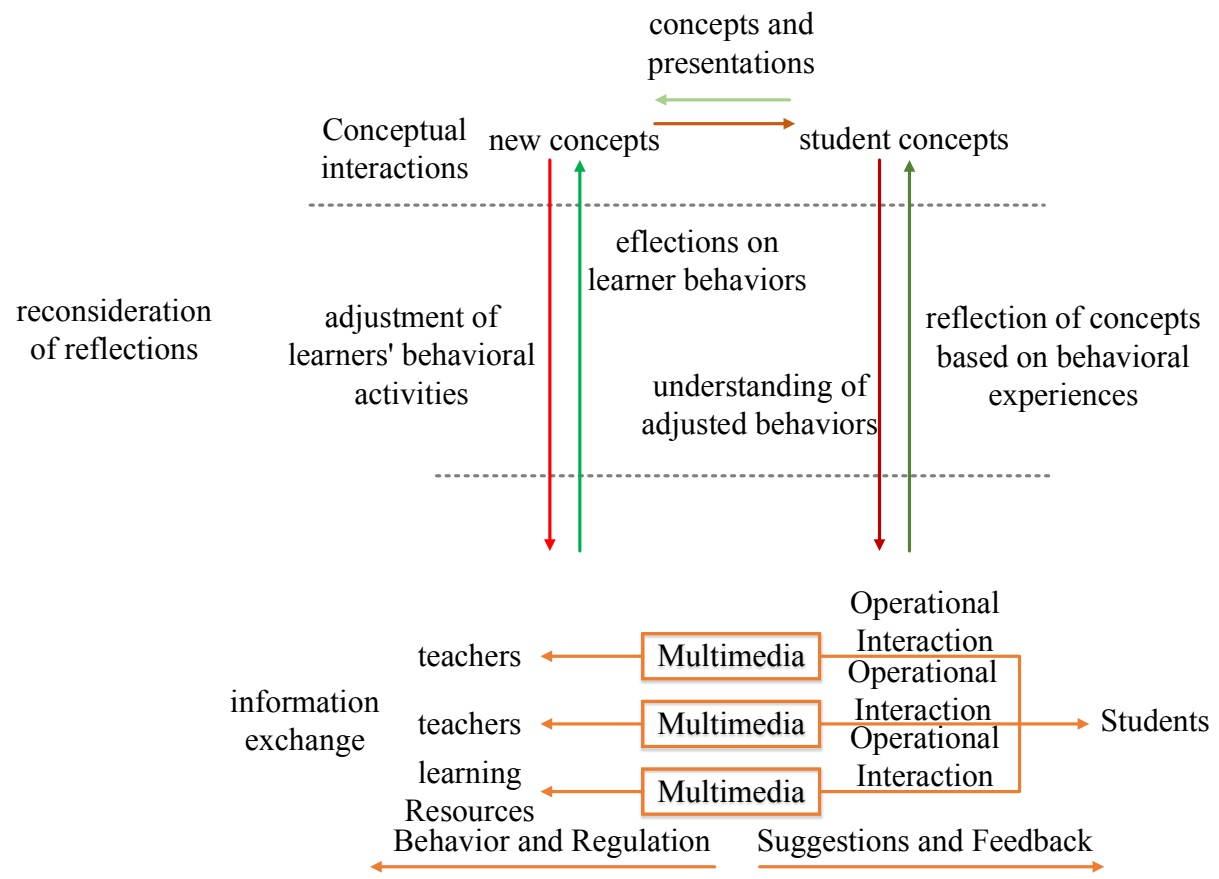

Fig. 1. Theoretical framework of applying interaction theory to distance education 


\subsection{Integrating distance education database technology into the teaching of Cross Talk}

Distance education database technology is another technology used in the new distance teaching model proposed in this study. The main features of this database platform include: the teaching data storage end, the distance teaching data end and the open teaching data end stored on the server, wherein, the teaching data storage end consist of an account database, course database, periodical learning allocation database, learning resource database, test question database, knowledge question database, exam question database, scoring database and learning progress database. These databases are mainly utilized as storage ends to provide course selection, periodical allocation, learning resources, test questions, knowledge questions, exam questions, scoring data and learning progress data for the entire distance education model, and achieve storage and transmission of these data. The whole structure of the distance education model that incorporates database technology is shown in Figure 2.

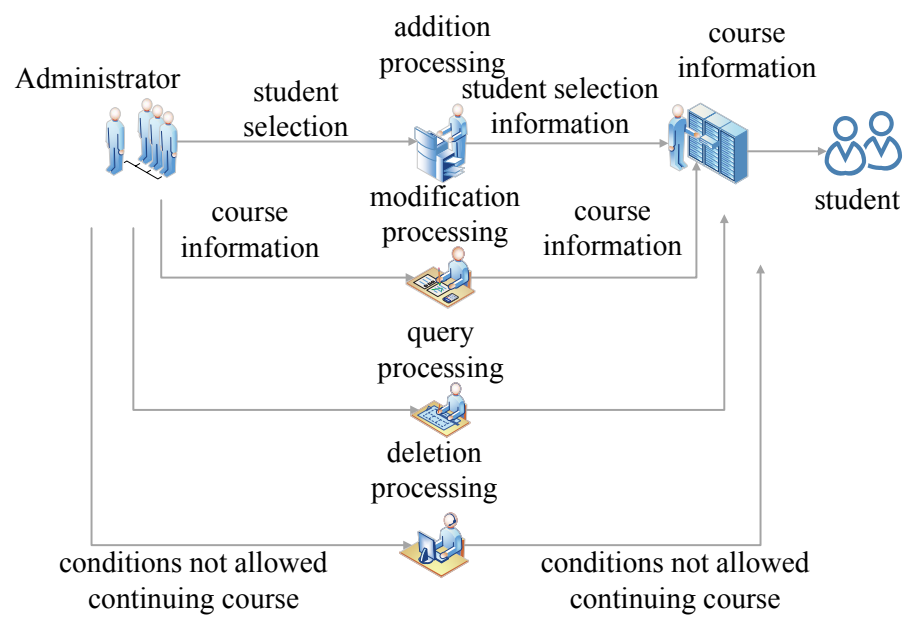

Fig. 2. Structure of the distance education model that incorporates database technology

Database technology for the entire distance education model includes different data tables, mainly stored in the form of memory. The entire process of memory storage runs mainly in accordance with the order of time to calculate the memory storage location. The calculation process is shown in Formula (1) below:

$$
t m-t i=\mathrm{V} t
$$

$t m$ is the time for the entry of the mth data table; $t i$ is the time for the entry of the ith data table; $\mathrm{V} t$ is the time difference between the two data tables. After determining the time difference between the data tables, it is necessary to decide the length $\mathrm{L}$ of the stored data table. The length of the entire data table is the sum of the length of each data table. The length of each data table is calculated in Formula (2) below. 


$$
I R=L T-L H
$$

IR is the length of a single datum; LT is the tail location of a single data table; and $\mathrm{LH}$ is the header location of a single data table.

After determining the time difference between different data tables and the length of a single data table, it is possible to determine the relative position of its storage in memory. The distribution of locations of the entire database data memory is shown in Formula (3). Location is the location of data storage; RAM is the location of memory; $i$ is the data sequence.

$$
\text { Location }=\frac{R A M \times \sum_{i=1}^{m}(1+I R)^{t_{m}-t_{i}}}{(1+I R)^{t_{m}-t_{0}}}
$$

\subsection{Integrating micro-video real-time transmission algorithm into the teaching of Cross Talk}

In the whole process of micro-video transmission, it is necessary to ensure the corresponding real-time and high transmission quality requirements, and the transmission efficiency must be guaranteed under limited bandwidth resources. Therefore, AIMD Algorithm was used in this study to optimize the entire data stream transmission. Specifically, AIMD algorithm can be represented by Formula (4).

$$
X(i+1)=\left\{\begin{array}{lll}
X(i) \times A & T(i)>k 2 & (0 \leq A \leq 1) \\
X(i)+B & T(i) \leq k 1 & (0 \leq B)
\end{array}\right.
$$

$X(i+1)$ and $X(i)$ are the transmission rates of the data streams at different times. $\mathrm{A}$ and $\mathrm{B}$ are the corresponding algorithm calculation factors. $\mathrm{T}$ (i) is the packet loss rate during the entire data stream transmission process. $\mathrm{k} 1$ and $\mathrm{k} 2$ are limiting critical values.

At the beginning of the entire data stream transmission process, the multiplication factor is set as a constant and the addition factor as the transmission rate of the previous period, where $\mathrm{C}$ and $\mathrm{Z}$ are respectively set within $(1,+\infty)$ and $(0,1)$, as shown in Formula (5).

$$
A=Z \quad B=C \times X(i)
$$

At the same time, the beginning of the data stream transmission is decided according to the requirements in Formula (6). The micro-video data stream can be transmitted only when it meets the formula.

$$
X(i)<\frac{X}{2} \quad X(i)+Z<X
$$


During the whole transmission process, the transmission rate of the data stream shows a corresponding slow growth state. The algorithm of A and B in the whole transmission implementation algorithm is determined as shown in Formula (7).

$$
A=a \times(X-X(i)) \quad B=C(0<a<1)
$$

If the growth rate is too fast in the entire video data stream transmission process, which results in a large proportion of the transmission channel and bandwidth resources, the value of B needs to be increased in the entire transmission algorithm as shown in Formula (8).

$$
A=a \times(X-X(i)) \quad B=C \times X(i)(0<a<1)
$$

\subsection{Integrating new distance education information technology into the teaching of Cross Talk}

Cross Talk, belong to art courses, was chosen as the main teaching experiment course of the distance education model proposed in this study. The preceding part has stated that the failure to vividly express the main teaching content of the whole course is the main problem in the teaching of art courses and leads to the low interest and enthusiasm of distance education learners. In this distance education model, a good learning condition is created for users mainly in the form of micro-video, with vivid, lively and diversified presentation methods. This is the most important part of the multimedia module of the entire education model. Sufficient courseware resources are provided in the entire distance education model provides, and students have access to the corresponding Q\&A module. The framework and idea of the entire distance education model are shown in Figure 3 and Figure 4.

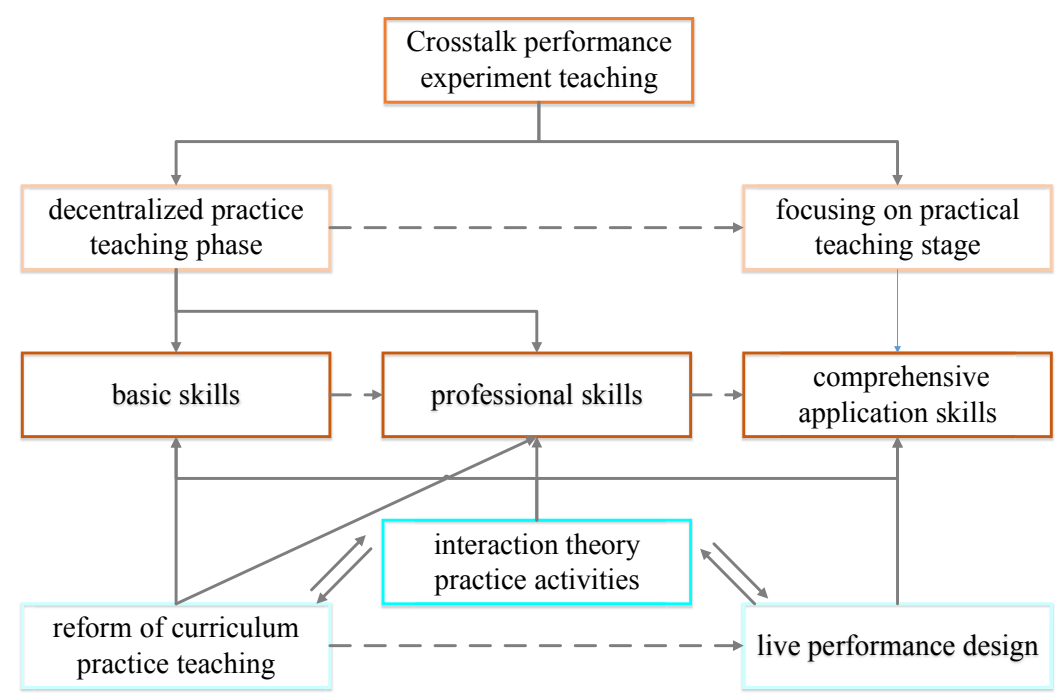

Fig. 3. Chart of the teaching content reform idea 


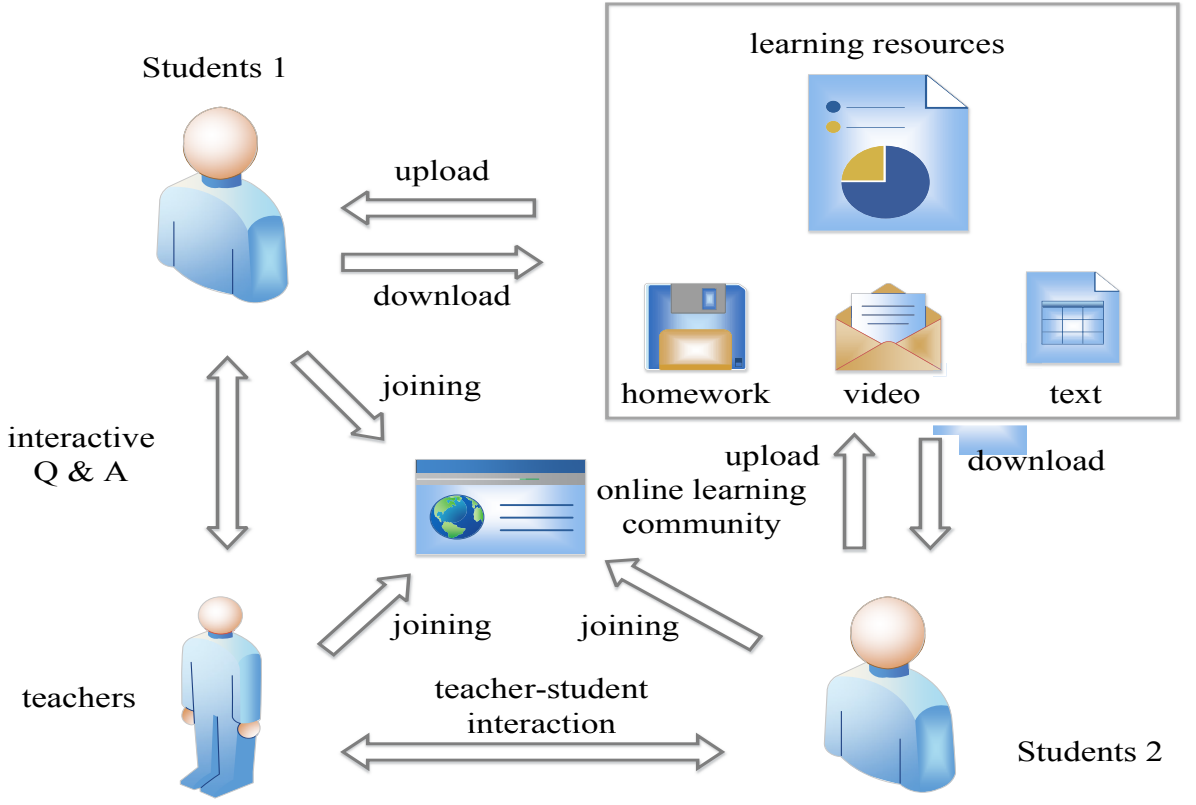

Fig. 4. Flow chart of the teaching reform idea

\section{Teaching Case and Teaching Effect}

\subsection{Teaching case}

Teaching resources throughout the course include micro-video resources and course resources, which are stored in the system database in the form of data packets. The physical form of the system database is memory. The entire teaching resource module includes two parts: course information and assignment information.

Course Information. This part of the learning module offers an overview of the course of Cross Talk, including course objectives, teaching plans, course arrangements, experiment arrangements, etc. In the online course module, students can fully understand relevant information and notifications of the course. At the same time, teachers can publish related preview materials before class so that students can synchronize with the class content in the class.

Assignment Information. This part covers the release of assignment information, uploading of students' assignment, and teachers' online correction of the assignment. Before the deadline for the assignment, students can upload their assignment at any time, and teachers can check online at any time. Besides, students can upload related multimedia audio and video works through this platform. With the teaching resource module, the platform can store video performance information recorded by students, so that teachers can trace students' learning situation in many aspects by using the distance teaching model. Figure 5 and 6 illustrate the application of micro video in the new distance education model. 


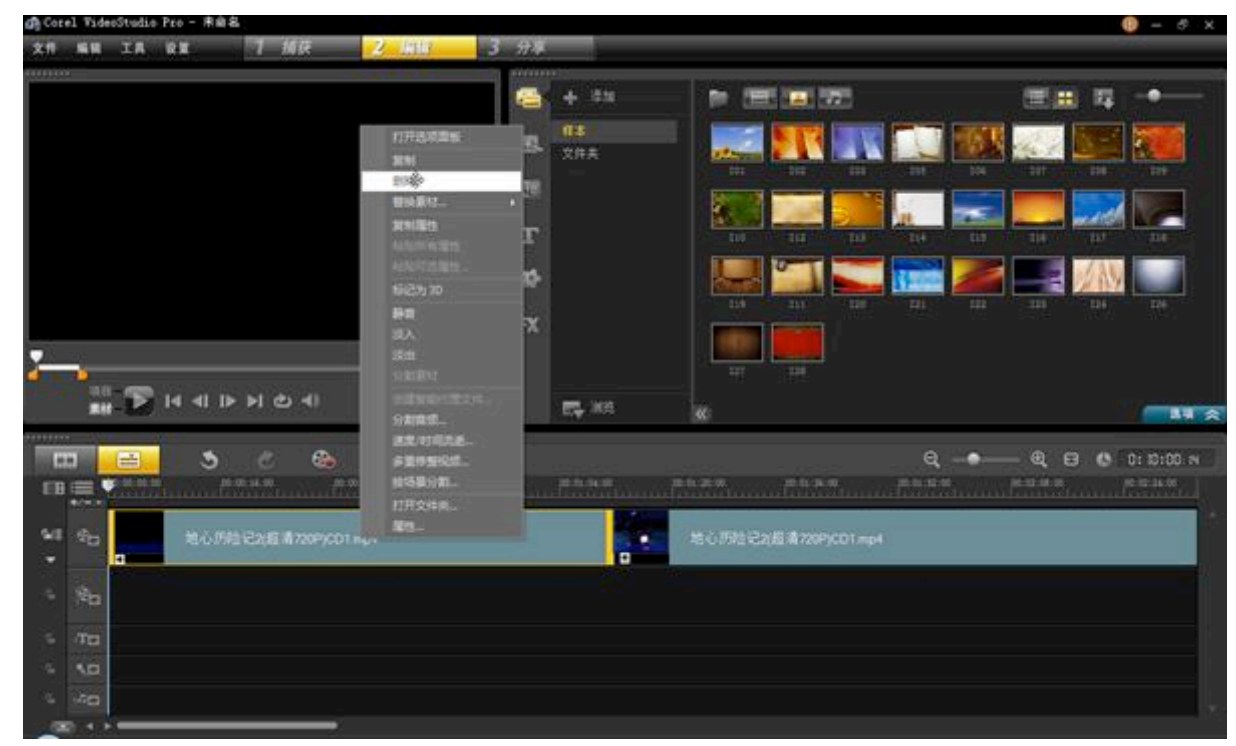

Fig. 5. Screenshot I of application of micro video in the new distance education model

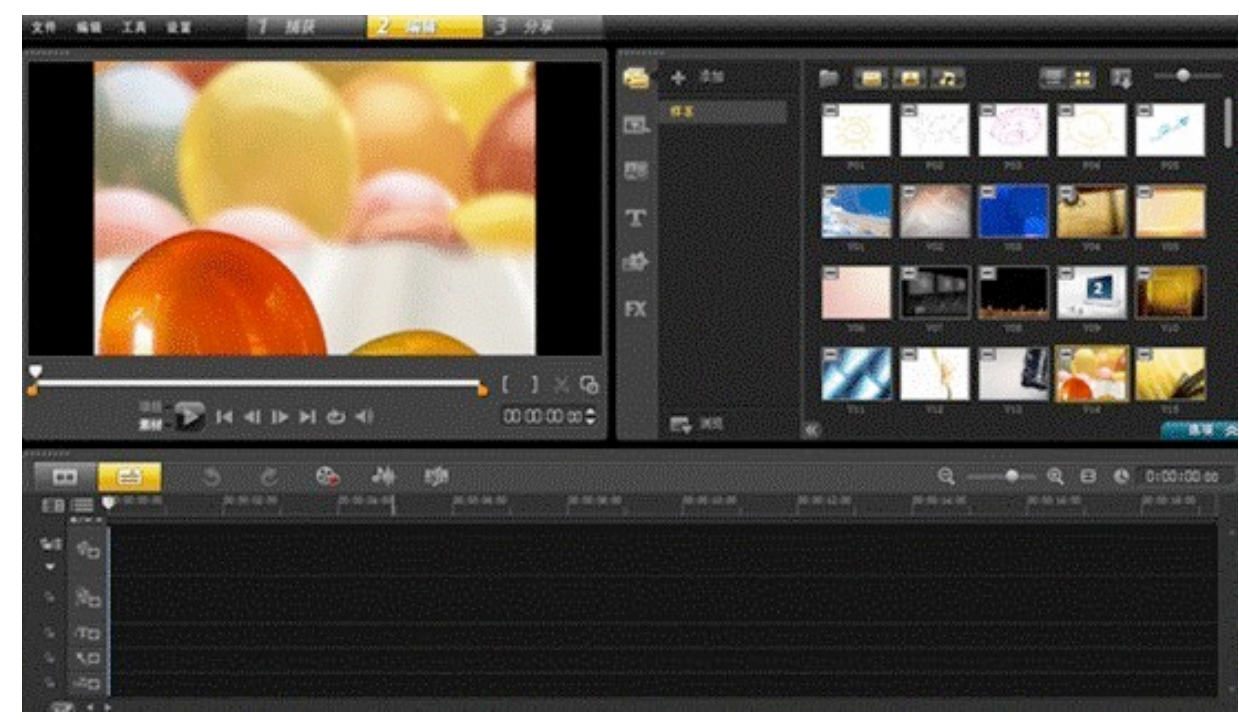

Fig. 6. Screenshot II of application of micro video in the new distance education model

The focus of the entire multimedia teaching module is learning based on video resources. In the video learning process, dichotomy can be found on all video learning interfaces. The upper part is the video playing interface with the width-height ratio of 800: 600. Meanwhile, the lower part of the entire learning interface offers the video title, learning duration and introduction of the main content, so that students can have a more in-depth understanding of the corresponding learning content. The existing 
excellent video resources of Cross Talk are also available. Teaching resources can be displayed for students in the form of text and video. The entire playing interface is simple and beautiful, facilitating students' operation in the learning process. The video learning interface of the entire system is shown in Figure 7.

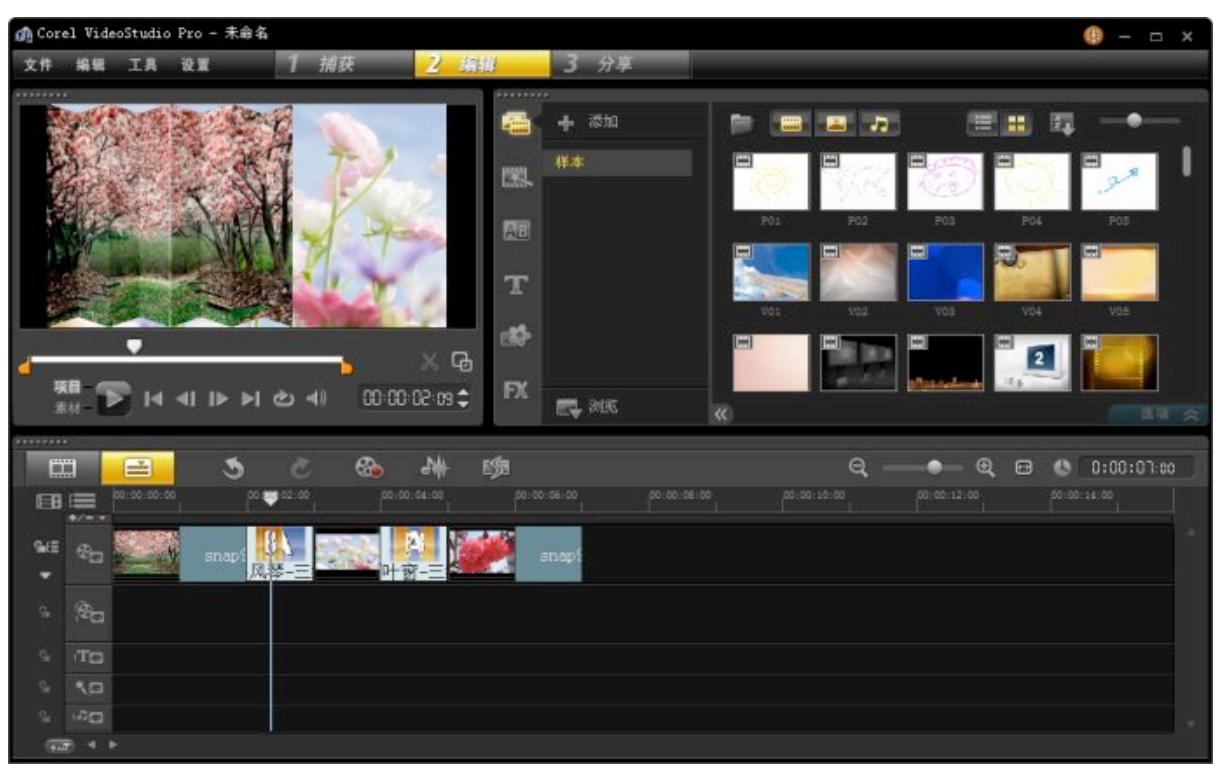

Fig. 7. On-site learning of Cross Talk in the new distance education mode

The interaction module of the entire distance education model is mainly divided into three parts: student-learning resource interaction, student-student interaction, and student-teacher interaction.

Student-learning resource interaction. Learning resources and the course content should be integrated first for students to engage in the interaction with learning resources. Due to the short playing time of the micro-video teaching content, microvideo resources should be designed in accordance with learners' cognitive development in order to ensure that the whole teaching video is lively and interesting, to convey knowledge within the effective time while making sure that the learning content is rich and complete.

Student-student Interaction. Course discussions and course performances were mainly set in this study to promote the sharing of experience and emotional communication between students. The use of discussion community is helpful for the completion of student-student communications. In addition, a collaborative video conferencing system was developed to enhance the exchange of video learning experience among students, in order to enhance the communication and interaction among students, enhance their experience and create an attractive atmosphere.

Student-teacher interaction. Teachers, as the guiders and facilitators in distance education, produce influence in the learning process and learning activities mainly through learning media, learning guidance and other forms. Students ask teachers 
questions concerning Cross Talk, and teachers pass the processed knowledge in a scientific way to students through micro-video or text. This is a way for teachers to act on students.

\subsection{Teaching effect}

Cross Talk is a course for undergraduates majoring in Quyi (Chinese folk art forms). A total of 327 users of the distance education model in 2017 as the research object to investigate the effect of using the new distance teaching model. The 327 respondent were randomly divided into two groups: 167 in the experimental group and 160 in the control group. The control group used the traditional distance education model. 327 copies of the questionnaire were sent out and 327 copies were collected, meaning that the recovery rate is $100 \% .325$ copies are valid, suggesting an effective questionnaire rate of $99.4 \%$. Invalid copies are those with some omitted questions. SPSS was used in this study to analyze the research results. Table 2 demonstrates how the users scored their own learning attitude before using this new distance education model.

Table 3 shows the scores of different learning attitudes of the respondents in different dimensions after using the distance education model.

Table 1. Top 5 and bottom 5 items in the scoring of platform users' learning attitude $(\bar{x} \pm s)$

\begin{tabular}{|c|c|c|c|}
\hline Order & No. & Item & Scores \\
\hline \multirow{5}{*}{ Top 5} & 12 & Passing the exam is enough, and there is no need to study hard & $4.5 \pm 1.33$ \\
\hline & 8 & Cross Talk is closely related to engagement in art work & $4.4 \pm 1.31$ \\
\hline & 7 & Having a welcomed show of Cross Talk gives me a sense of accomplishment & $4.2 \pm 0.83$ \\
\hline & 16 & $\begin{array}{l}\text { Cross Talk has no technologic element and I can practice it after watching } \\
\text { look }\end{array}$ & $4.1 \pm 1.02$ \\
\hline & 12 & Engagement in Cross Talk related work gives me a sense of accomplishment & $4.0 \pm 0.96$ \\
\hline \multirow{5}{*}{ Bottom 5} & 3 & I often search Cross Talk information online & $2.5 \pm 0.74$ \\
\hline & 9 & I often take a variety of ways to obtain Cross Talk skills & $2.9 \pm 1.23$ \\
\hline & 4 & I will ask the teacher when encountering a problem I do not understand & $3.0 \pm 0.53$ \\
\hline & 2 & I review the learning content only before the exam & $3.2 \pm 1.44$ \\
\hline & 18 & I will preview before each class & $3.3 \pm 1.13$ \\
\hline
\end{tabular}

Table 2. Comparison of scores of the two groups' learning attitude in each dimension $(\bar{x} \pm s)$

\begin{tabular}{|c|c|c|c|c|c|}
\hline Item & $\begin{array}{c}\text { Leaning } \\
\text { interest }\end{array}$ & $\begin{array}{c}\text { Learning } \\
\text { experience }\end{array}$ & $\begin{array}{c}\text { Personal learn- } \\
\text { ing habit }\end{array}$ & $\begin{array}{c}\text { Knowledge } \\
\text { of Cross Talk }\end{array}$ & Mean \\
\hline Experimental group $(\mathrm{n}=165)$ & $4.89 \pm 0.63$ & $4.54 \pm 0.57$ & $4.57 \pm 0.52$ & $4.47 \pm 0.33$ & $4.76 \pm 0.56$ \\
\hline Control group $(\mathrm{n}=160)$ & $4.1 \pm 0.32$ & $3.79 \pm 0.34$ & $3.96 \pm 0.53$ & $3.19 \pm 0.23$ & $3.68 \pm 0.62$ \\
\hline $\mathrm{T}$ & 0.775 & 0.865 & 0.689 & 1.345 & 1.187 \\
\hline $\mathrm{P}$ & 0.274 & 0.075 & 0.001 & 0.513 & 0.063 \\
\hline
\end{tabular}


From the students' evaluation of their learning experience in the whole course, it can be observed that there is a gap in the course learning experience between those who used the new distance education model and those who used the traditional distance education model. Compared with the latter, the former could gain more control over the whole course, and obtain more in-depth understanding and comprehension of the corresponding Cross Talk knowledge. As for the students who used the traditional distance education model, it was concluded from the respondents' feedbacks that the corresponding theoretical knowledge of Cross Talk is rather complicated and the traditional learning way does not assist the users to have a clear understanding of the entire course, leading to the poor learning experience of these students in the course of Cross Talk.

Judging from the personal learning habit and understanding of Cross Talk among the respondent after learning the course, it can be seen that there is still gap between the experiment group and the control group in relevant scores. The average score of those students who used the new distance teaching model in personal learning habit and knowledge of crosstalk is higher than that of those who used the traditional distance education model. From the single level of learning effect, we can see that the new distance education model brings more obvious improvement to students.

\section{Conclusions}

By comparing the traditional teaching model and the reformed teaching mode, it was found that the Cross Talk teaching model based on the new distance education information technology can make up for the deficiencies of the traditional teaching model and improve students' learning attitude, concretely manifested is the following aspects:

1. The distance education model effectively combines the usual learning of theoretical knowledge with actual cross talk, efficaciously enhancing students' learning effect in the art course of Cross Talk.

2. Using the reformed interactive teaching model, teachers can trace students' learning progress at any time, and adjust the teaching content according to students' understanding and comprehension of new knowledge. At the same time, the model can improve students' ability to innovate and solve problems, and correspondingly expand teachers' understanding of students in order to better "teach students according to their aptitudes."

3. The use of the teaching model put forward in this study reinforces students' cognition of their major, enables them to more intuitively recognize the art charm of Cross Talk, and leads them to meet the social needs for graduates of art performance.

In conclusion, this reform of the teaching model for Cross Talk has been approved by teachers and students, and the teaching effect shows that this teaching model can be promoted in the teaching of other majors. 


\section{References}

[1] Liu, W.M., Wu, R.M., Lin, J.W., Liu, Y.C., Chang, C.H., \& Lin, C.H. Time trends in the prevalence and incidence of Parkinson's disease in Taiwan: a nationwide, populationbased study. Journal of the Formosan Medical Association, 2016, vol. 115(7), pp. 531-538. https://doi.org/10.1016/j.jfma.2015.05.014

[2] Reed, K. Teaching science and technology via online distance learning: the experience of teaching biostatistics in an online master of public health programme. Open Learning: The Journal of Open, Distance and e-Learning, 2011, vol. 26(2), pp. 165-171.

[3] $\mathrm{Lu}, \mathrm{F}$. Investigation on the characteristics of college English learners at Haining learning center under ocec, southwest university. Journal of Huzhou Vocational \& Technological College, 2015, vol. 15(1), pp. 13-18.

[4] Yang, T.Y. Reform program of practicing concept of scientific development in distance and continuing education colleges. Continue Education Research. 2010, vol. 15(6), pp. 1719.

[5] Alghali, A.M., Turay, E.D.A., Thompson, E.J.D., \& Kandeh, J.B.A. Environmental scan on education in sierra leone with particular reference to open and distance learning and information and communication technologies. Commonwealth of Learning, 2005, vol. 50(2), pp. 54.

[6] Dziva, D., Kusure, L., Bhukuvhani, C., Mhishi, M., Muvindi, I., \& Zuvalinyenga, D., et al. Attrition of pre-service student science teachers under the virtual, open and distance learning (vodl) mode at bindura university of science education (buse) in zimbabwe. Educational Journal of the University of Patras Unesco Chair, 2015, vol. 2(1), pp. 25-34.

[7] Malinovski, T., Vasilevastojanovska, T., Jovevski, D., Vasileva, M., \& Trajkovik, V. Adult students' perceptions in distance education learning environments based on a videoconferencing platform--qoe analysis. Journal of Information Technology Education Research, 2015, vol. 14(1), pp. 1-19.

[8] Art, K., \& Maddux, C.D. Interactive televised distance learning versus on-campus instruction. Journal of Research on Technology in Education, 2001, vol. 34(1), pp. 87-91. https://doi.org/10.1080/15391523.2001.10782336

[9] Smith, S.J., \& Harvey, E.E. K-12 online lesson alignment to the principles of universal design for learning: the khan academy. Open Learning: The Journal of Open, Distance and eLearning, 2014, vol. 29(3), pp. 222-242.

[10] Chen, Y.M., Song, S.J., Domain transfer extreme learning machine and its application on domain adaptation problems. China Sciencepaper, 2017, vol. 14, pp. 1565-1569.

[11] Jin, G.D., Zhang, X.Y., \& Cai, C.C. The construction and exploration of network teaching platform for the course food inspection and analysis. Journal of Yangzhou College of Education, 2012, vol. 101-102(3), pp. 3-11.

[12] Zhu, B.F., Pan, F., Shen, C.M., Yan, J.W., Wang, H.D., \& Guo, J.X., et al. Population genetics and forensic efficiency of twenty - one novel microsatellite loci of Chinese yi ethnic group. Electrophoresis, 2013, vol. 34(24), pp. 3345-3351. https://doi.org/10.1002/elps. 201300362

\section{$7 \quad$ Author}

Zhuang ZHOU is a Lecturer in the University of Science and Technology Liaoning, Anshan 114051, China. (zhouzhuangaskd@163.com).

Article submitted 17 March 2018. Final acceptance 23 April 2018. Final version published as submitted by the author. 